\title{
ANALISE GEOMÉTRICA E CINEMÁTICA DAS ROCHAS METASSEDIMENTARES DA REGIÃO DE IJACI, SUL DE MINAS GERAIS
}

\section{NOLAN MAIA DEHLER* \& RÔMULOMACHADO**}

\begin{abstract}
GEOMETRIC AND KYNEMATIC ANALYSIS OF METASSEDIMENTARY ROCKS OF THE IJACI REGION, SOUTHERN MINAS GERAIS This paper presents the results of geological mapping undertaken in the Ijaci region, southern Minas Gerais State. Two lithostructural domains were distinguished: the basement domain, composed by orthogneisses of granitic to granodioritic composition, characterized by an older foliation of E-W tectonic steeply dipping to north or south; and the metasedimentary cover domain, composed at the base by a marble unit overlain by phyllites interlayered with quartzite units. A low angle tectonic, south-dipping foliation, and a down-dip mineral stretching lineation characterize this domain. Kinematic indicators, such as S-C foliation and asymmetrical folds, locally sheath folds, are consistent with a top to NNW shear sense. The metamorphic assemblage of the foliation indicates greenschist facies conditions (biotite zone). The rheological contrast between the two domains, the nature of the metasedimentary cover deformation and the mylonitic character of the metasediments suggest an allochtonous character for the cover rocks. Finally, it may be concluded that the metasediments undenvent thin-skinned deformation, associated to thrust movement vergent to the stable área the São Francisco Craton, similar to a foreland region.
\end{abstract}

Keywords: metasedimentary cover, kinematic, progressive deformation, rheological contrast

RESUMO O presente trabalho apresenta os dados obtidos com o mapeamento geológico da região de Ijaci, Sul do Estado de Minas Gerais. Foram identificados dois domínios litoestruturais distintos: o Domínio do Embasamento, composto por ortognaisses, é caracterizado por uma foliação tectônica de direção geral E-W e mergulhos subverticais; e o Domínio da Cobertura Metassedimentar, objetivo principal deste trabalho, composto na base por uma unidade de mármores calcíticos e, no topo, por uma unidade de filitos e quartzitos interestratificados. Este domínio é caracterizado por uma foliação tectônica principal, com mergulhos sub-horizontais para sul, associada a uma lineação de estiramento mineral de mergulho. Os indicadores cinemáticos associados à foliação principal, como pares de foliações S-C e dobras consistentemente assimétricas, são compatíveis com uma movimentação de topo para NNW. Estudos de microtectônica sugerem que a foliação principal se desenvolveu em condições metamórficas da fácies xisto verde, zona da biotita. Este estilo estrutural, ausente nas rochas de embasamento, juntamente com a natureza não-coaxial da deformação principal nos metassedimentos e o caráter milonítico dos mesmos, sugere aloctonia das rochas da cobertura. Outras estruturas, como dobras e zonas de cisalhamento discretas, superpõem-se à estruturação principal dos metassedimentos, e seu agrupamento em fases de deformação é discutido neste trabalho. Finalmente, conclui-se que os metassedimentos, na área em questão, sofreram uma deformação do tipo epidérmica, com vergência de suas estruturas para um núcleo mais antigo situado a norte, representado pelo Cráton do São Francisco.

Palavras-chave: cobertura metassedimentar, cinemática, deformação progressiva, contraste reoló gico

INTRODUÇÃO A região que compreende o bordo sul do Craton do São Francisco, na porção meridional do Estado de Minas Gerais e, subordinadamente, em suas partes adjacentes situadas nos Estados do Rio de Janeiro e São Paulo, tem sido objeto de mapeamentos geológicos sistemáticos desde as décadas de 50 e 60 , com os trabalhos tendo sido iniciados por Ebert $(1955,1956 \mathrm{a}, 1956 \mathrm{~b}, 1958$, 1968). Nesta ocasião, definiu a estratigrafia básica da região, constituída pelos Grupos São João del Rei e Andrelândia, de idade Algonquiana. Além disso, reconheceu nos arredores de São João del Rei rochas mais antigas, Arqueanas, incluídas na Série Barbacena (Barbosa 1954), restringidas agora pelo autor as rochas do embasamento (Ebert 1957). Reconheceu a existência de uma discordância estrutural entre estas duas unidades, e assinalou diferenças de estilos estruturais entre elas. Descreveu também a presença de veios graníticos e pegmatíticos que afetam apenas as unidades mais antigas (Ebert 1955). Explica as diferenças litológicas entre os Grupos São João del Rei e Andrelândia pelas variações faciológicas laterais através de uma mesma bacia. Caracteriza ainda um zoneamento metamórfico regional crescente para sul, passando de epizonal, região de São João del Rei, a mesozonal, região de Andrelândia, e catazonal, nas regiões de Varginha e vale do Paraíba do Sul (Ebert 1955,1984). Paralelamente, define para a região um modelo tectônico com falhas de empurrão e nappes associadas, com vergência geral para norte em direção ao antepaís (Ebert 1955, 1956a, 1956b). Os trabalhos do autor culminaram com a proposição de um modelo tectônico regional, onde são reconhecidas estruturas mais novas, denominadas Paraíbides, que truncariam estruturas mais antigas, Araxaídes (Ebert 1968,1971).

Estratigrafícamente, o Grupo São João del Rei foi dividido, da base para o topo, nas Formações Tiradentes, Carandaí e Prados (Ebert 1956a), sendo incluídas posteriormente as Formações Barroso (parte superior da Formacão Carandaí) (Ebert 1956b) e Rio das Eivas, na base do grupo (Ebert 1984). Na região de Ijaci (zona de Lavras), a existência de uma unidade sedimentar acima dos calcários da Formação Barroso, constituída de arenitos, grauvacas e arcóseos, com características sedimentares diferentes da Formacão Prados de outras regiões (zonas de São João del Rei e Carandaí), foi denominada de Formação Macaia (Ebert 1984)

A partir da década de 80, inicia-se uma fase importante de trabalhos de mapeamento geológico sistemático na região, conduzidos principalmente por Trouw et al. $(1980,1982,1983,1984,1986)$, Ribeiros et al (1990) e Andreis et al. (1989), que confirmam em linhas gerais a proposta estratigráfica de Ebert. Os autores definem inicialmente o Grupo Carrancas, subdividido nas Formações São Tomé das Letras e Campestre, considerando-o como uma unidade transicional entre os Grupos
São João del Rei e Andrelândia. Posteriomente, abandonam esta ideia, retomando a estratigrafia original de Ebert. Como decorrência destes trabalhos, foi definido um esquema de evolução estrutural baseado em três fases de deformação, D1, D2 e D3, com as duas primeiras, acompanhadas de metamorfísmo regional $\mathrm{Ml}$, relacionadas ao ciclo Uruçuano (entre 1400 e $1000 \mathrm{Ma}$ ), e a última (D3), com metamorfísmo M2, ao ciclo Brasiliano (entre 640 e $450 \mathrm{Ma}$ ) (Trouw et al. 1980,1982, 1983, Heilbron et al 1989, Ribeiro et al. 1990). No primeiro evento, a movimentação tectônica teria se processado de oeste para leste e de sul para norte, enquanto no segundo, teria envolvido uma compressão leste-oeste (Ribeiro et al. 1990). Foram também definidos os ciclos deposicionais Tiradentes (base), Lenheiro, Carandaí e Andrelândia (topo), com idade atribuída ao Paleo a Mesoproterozóico (Andreis et al. 1989a). Estes ciclos representam sobretudo depósitos plataformais e litorâneos, com o primeiro e os dois últimos sendo relacionados a transgressões na bacia (Andreis et al. 1989a e 1989b, Ribeiro et al. 1990). Entre os ciclos Lenheiro e Carandaí ocorre uma discordância angular, já reconhecida anteriormente por Ebert (1956).

$\mathrm{E}$ ainda deste período a definição das unidades que compõem o embasamento na região, correspondentes aos Grupos Mantiqueira e Barbacena, Formação Lafaiete e Gnaisses Piedade (Barbosa 1954, Ebert 1955, 1956a e 1956b).

A ocorrência de uma área de metassedimentos ainda não estudada na região de Ijaci, sul do estado de Minas Gerais, correlacionável com as unidades acima discutidas, cujos problemas estratigráficos, estruturais e tectônicos não foram ainda inteiramente equacionados, constituíram-se nos principais motivos para a realização deste trabalho. Para isso, foi efetuado um mapeamento geológico-estrutural em escala 1:25.000 da área de ocorrência dos metassedimentos, com aplicação das técnicas modernas de análise estrutural, dando ênfase nos elementos da análise cinemática das estruturas, como pares S-C de foliações, assimetrias das dobras, bandas de cisalhamento e lineações de estiramento mineral. Paralelamente, foram efetuados estudos petrográficos e de microtectônica, visando caracterizar às condições metamórficas e a sua relação com a deformação.

A região estudada situa-se, do ponto de vista tectônico, na borda sudoeste do Cráton do São Francisco, próximo ao limite que separa esta unidade cratôníca da Cunha de Guaxupé (sensu Wernick et al. 1981) e da Faixa Alto Rio Grande (Fig. 1).

CONTEXTO TECTÔNICO REGIONAL Com os trabalhos sistemáticos de Trouw e colaboradores, a partir da década de 80 , enfatizando a cobertura metassedimentar do bordo Sul do Cráton do São Francisco, juntamente com diversos outros trabalhos regionais,

* CPRM-SP e pós-graduando do Instituto de Geociências da USP, e-mail: nokontiki@hotmail.com

** Instituto de Geociências da USP e Pesquisador do CNPq, Rua do Lago 562, Cidade Universitária, 05508-900, São Paulo-SP, FAX (011) 8183993, e-mail: rmachado@usp.br 


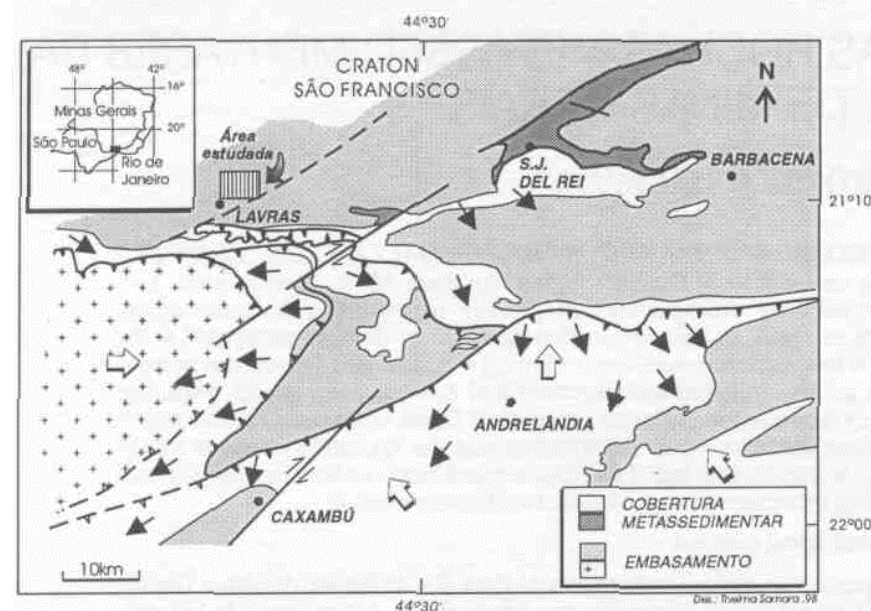

Figura l - Mapa tectônico da extremidade Sul do Cráton do São Francisco com a localização da área estudada (modificado de Ribeiro et al 1990).

como os de Campos Neto (1991), Campos Neto et al.(1990), Ribeiro et al.(1990), Tassinari(1988), Heilbron(1993), Heilbron et al.(1994),Machado \& Endo (1993a, 1993b, 1994), Endo \& Machado (1993),Ebert et al.(1993a e 1993b), Trouw et al.(1994)e Trouw (1995), dentreoutros, tem sido propostos modelos distintos para explicar a evoluçãoestrutural dos metassedimentos da Faixa Alto Rio Grande (Hasui \& Oliveira 1984), e também para toda a Faixa Ribeira. Nestes modelos, uma discussão importante é o papel desempenhado pelas transcorrências no arcabouço estrutural de ambas as faixas.

Em linhas gerais, os modelos estruturais podem ser agrupados da seguinte maneira:

(a) Modelo Tangencial Polifásico, em que a estruturação das rochas metassedimentares dos Grupos Andrelândia e São João del Rei seria decorrente de fases de deformação superpostas associadas ao mesmo ciclo geotectônico (modelo monocíclico) ou a ciclos geotectônicos distintos (modelo policíclico). Nesta concepção, Trouw et al.(1986) e Ribeiro et al. (1990) sugerem duas fases progressivas de caráter tangencial D1+D2, com vergência heterogê-nea, para NNW e E, como responsáveis pela estruturação principal das rochas metassedimentares. Os mesmos autores identificam ainda a fase de deformação D3, superposta à estruturação tangencial, associada às importantes zonas de cisalhamento destrais de direção NE-SW. Segun do Ribeiro et al.(1990), as fases D1+D2 seriam do ciclo Uruaçuano (1400-1000 $\mathrm{Ma}$ ), enquanto a fase D3, do ciclo Brasiliano (650-450 Ma). Desta maneira, os autores consideram uma evolução policíclica para as fases de deformação. Este mesmo tipo de evolução, porém en- volvendo cinco fases de deformação, também é postulado para Faixa Alto Rio Grande por Campos Neto (1991). Contudo, trabalhos mais recentes têm considerado uma evolução monocíclica vinculada ao ciclo Brasiliano (Trouw \&Punkhurst 1993, Machado \& Endo 1993a, 1993b, Heilbron et al. 1994). Para Heilbron et al. (1994) e Campos Neto (1991), as transcorrências representariam um estágio tardio no contexto da evolução tectônica brasiliana, ocasião em que a deformação colisional não poderia mais ser resolvida por falhas de empurrão, passando então a desenvolver as transcorrências. Heilbron et al. (1994) identificam ainda uma fase mais nova, D4, de caráter distensivo. Trouw et al. (1994) sugerem também que as estruturas com vergência para NNW, anteriormente consideradas como responsáveis pela estruturação principal das rochas metassedimentares (Ebert 1955, Trouw et al. 1980, 1983, 1984, 1986), seriam distribuídas em zonas estreitas, superpondo-se a uma estruturação mais antiga, com vergência para E;

(b) Modelo Transpressivo (Machado \& Endo 1993a, 1993b, Endo \& Machado 1993), segundo o qual os empurrões e demais feições contracionais associadas, situadas nas porções mais externas do orógeno transpressivo (i.e., na Faixa Alto Rio Grande, limite Sul do Cráton do São Francisco), seriam concomitantes com às zonas de cisalhamento de alto ângulo desenvolvidas na zona interna deste mesmo orógeno (i.e., no Sistema de Cisalhamento Paraíba do Sul). Segundo este modelo, a evolução tectono-metamórfica teria se dado durante o neoproterozóico. Ebert et al. (1993b) reforçam a importância da tectônica transpressiva na estruturação do limite Sul do Cráton do São Francisco, considerando, entretanto, a existência de uma tectônica tangencial mais antiga, com vergência para norte. Para Trouw (1995), o padrão das lineações de estiramento mineral indica um caráter tardio para as transcorrências destrais, sugerindo, entretanto, uma movimentação tangencial de topo para NE, distinta daquela anteriormente postulada para NNW (Ebert 1968, Trouw et al. 1986, Campos Neto et al.1990, Heilbron et al. 1994).

GEOLOGIA LOCAL Os trabalhos de campo permitiram identificar dois domínios litoestruturais distintos: o Domínio do Embasamento, composto na área estudada por ortognaisses de composição granítica a granodiorítica, caracterizado por uma foliação tectônica de direção geral E-W e mergulhos subverticais; e o Domínio da Cobertura Metassedimentar, constituído, na base, por uma unidade de mármores calcíticos e, no topo, por uma unidade estratificada, composta por intercalações de filitos (xistos finos) e quartzitos. Este domínio é caracterizado por uma foliação tectônica de direção geral E-W e mergulhos sub-horizontais para sul. A delimitação destes dois domínios é encontrada na Fig. 2.

A unidade basal é composta por mármores de cores cinza esbranquiçado a branco acinzentado, de granulação fina a média, constituídos principalmente por calcita, quartzo e, subordinadamente, moscovita, clorita, biotita e minerais opacos. Esta unidade, na porção basal, é rica em lentes ou níveis de metapelitos, sendo representada por biotitaclorita-quartzo-moscovita filitos, localmente em associação com carbonato e minerais opacos, sendo frequente a presença de pirita. Esta unidade possui uma espessura aproximada de $600 \mathrm{~m}$.

A unidade superior é composta por intercalações de biotitamoscovita-quartzo-clorita filitos e de moscovita quartzitos, ambos de granulação fina. Os primeiros, quando não alterados, são de cor cinza esverdeado, e os últimos, branco acinzen- tado. Estas intercalações são observadas em todas as escalas, desde milimétrica até métrica. Em direção ao topo da unidade há uma tendência no aumento da proporção de níveis mais quartzosos. Localmente, os filitos apresentam grafita e pirita associadas. Esta unidade faz contato brusco com a unidade inferior e possui espessura entre 450 e $600 \mathrm{~m}$. Não foram ob- servadas estruturas primárias preservadas nas duas unidades.

ESTRUTURAS As estruturas mapeadas diferem em estilo e orientação nos dois domínios litoestruturais estudados. No domínio litoestrutural do embasamento, a estruturação principal é dada por uma foliacão milonítica de direção geral E-W, localmente defletida para $\mathrm{NNE}$, com mergulhos subverticais. Esta foliação desenvolveu-se de forma heterogênea, ora gerando domínios onde a foliação milonítica é mais penetrativa, com formação local de uma estrutura bandada, ou intercalando-se com domínios menos deformados, onde a textura ígnea é bem preservada (isótropa a levemente foliada).

Neste domínio, superpostas à foliação principal, foram observadas zonas de cisalhamento rúpteis, subparalelas à estruturação dúctil anterior. Estas zonas de cisalhamento, de direção geral E-W, mostram movimentações direcionais tanto destral quanto sinistrai (Dehler 1996), evidenciando assim a existência de estruturas com superposição cinemática, a exemplo do que foi descrito na porção meridional do Cráton do São Francisco e nos terrenos mais a sul do mesmo (Machado \& Endo 1994, Endo 1997). Cabe também assinalar que, na área estudada, além da escassez de estruturas dobradas nas rochas do embasamento, é muito difícil a caracterização das estruturas lineares.

As estruturas no domínio da cobertura diferem substancialmente, em estilo e orientação, das estruturas do domínio do embasamento, e seu estudo constitui o objeto principal deste trabalho. A seguir, é feita uma descrição detalhada do acervo estrutural das rochas da cobertura, juntamente como as interpretações decorrentes das observações efetuadas neste trabalho.

Fase de deformação principal (Dn) da Cobertura A fase de deformação principal (Dn), que afetou as rochas metassedimentares mapeadas, foi responsável pela estruturação deste domínio e também pela geração dos elementos estruturais da trama dúctil, penetrativos nos metassedimentos e associados à intensa recristalização, como a foliação milonítica penetrativa e a lineação de estiramento mineral. Outras estruturas, a exemplo das dobras assimétricas, são também atribuídas à esta fase de deformação, pois têm a foliação principal ( $\mathrm{Sn}$ ) como plano axial.

A foliação Sn, na unidade inferior, é caracterizada por uma clivagem ardosiana, geralmente paralela a um bandamento composicional, dado por intercalações entre bandas de metapelitos, formados por quartzo-clorita-moscovita filitos, localmente com biotita e carbonato, e bandas ricas em carbonato, onde a foliação é conferida pela orientação preferencial de minerais micáceos e grãos de carbonato e quartzo. Na unidade superior, a foliação Sn também corresponde a uma clivagem ardosiana, desenvolvida paralela a um bandamento composicional, dado por intercalações de bandas de quartzitos e de filitos. Mais 


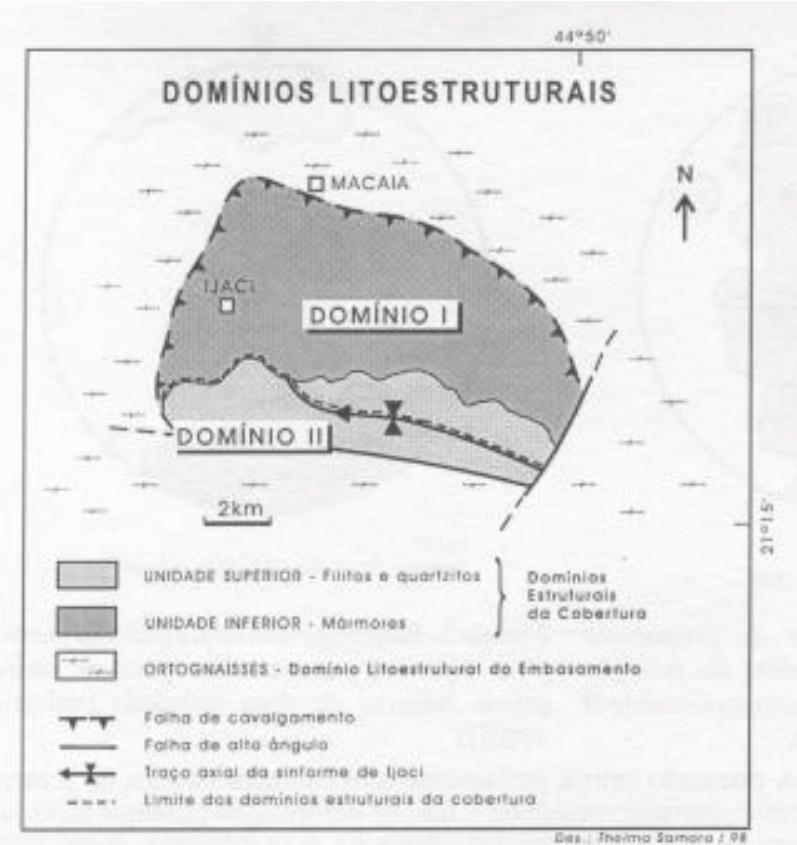

Figura 2 - Mapa com os domínios estruturais da região Ijaci (modificado de Dehler, 1996).

raramente, esta clivagem ardosiana é oblíqua ao bandamento composicional, sendo associada, frequentemente, à dobras. A atitude da foliação $\mathrm{Sn}$, nas rochas de cobertura, foi utilizada como critério para a delimitação dos domínios estruturais. O domínio I, a norte (Fig. 2), é caracterizado por uma estruturação relativamente simples, com a foliação Sn apresentando mergulhos suaves para sul (Fig. 3).

No domínio II, a sul, esta foliação tem um comportamento relativamente mais complexo. Mostra uma maior dispersão no estereograma, possibilitando entretanto a definição de uma guirlanda com eixo de caimento suave para W (Fig. 4).

Na superfície da foliação Sn observa-se uma lineação de estiramento mineral de mergulho, dada pela orientação de minerais micáceos e por agregados de quartzo e carbonato estirados. Esta lineação, observada mais frequentemente no domínio estrutural I, apresenta caimento suave dominante para sul, com máximo situado no setor SSE (Fig. 5).

Outra lineação observada no plano de foliação Sn é dada por neocrescimento de fibras de carbonato. Esta lineação é subparalela à lineação de estiramento mineral.

Os indicadores cinemáticos observados na área estudada foram pares de foliações S-C, dobras assimétricas e pods de foliações. Em alguns pontos, a foliação $\mathrm{C}$ é dada por bandas pronunciadas de espessura centimétrica, relativamente ricas em minerais micáceos, diferenciando-se da foliação $\mathrm{S}$ nos domínios intermediários, que exibem granulação mais fina e morfologia sigmoidal. A assimetria dos pares de foliações S-C (Berthé et al 1979, Lister \& Snoke 1984, Hanmer \& Passchier 1990) é compatível com uma movimentação geral de topo para NNW, durante esta fase de deformação (Dehler et al. 1995,1996, Dehler 1996), mostrando plano de cisalhamento mergulhando suavemente para sul (Fig. 6). A vergência sugerida pelas fibras de calcita é a mesma da deformação dúctil anteriormente descrita.

A paragênese metamórfica, observada no plano de foliação principal nos metapelitos, é composta por clorita + moscovita (fengítica) + quartzo + biotita + calcita + minerais opacos, característica da fácies xisto verde, zona da biotita (Yardley 1992).

Por todo o pacote metassedimentar são observadas dobras assimétricas de forma consistente, com vergência para NNW-NNE, tendo a foliação principal em posição plano-axial. Em perfil, são dobras fechadas a isoclinais, mostrando charneiras espessadas e agudas, com flancos adelgaçados. Frequentemente estão associadas com superfícies discretas de empurrão, decorrentes da intensificação das superficies de cisalhamento no flanco curto destas estruturas. São estruturas com arco externo mais fechado do que o interno, podendo ser classificadas como dobras da classe 3 de Ramsay (1967). Na classificação de Turner \& Weiss (1963), as dobras variam entre recumbentes a inclinadas. Outra característica destas estruturas é seu caráter acilíndrico, formando localmente dobras em bainha (Machado \& Dehler 1995). A assimetria das dobras, assim como o eixo X da dobra em bainha mapeada, é compatível com uma sentido de transporte tectônico para NNW (Machado \& Dehler 1995). O estilo das dobras associadas à fase Dn não é constante. Em perfil, elas variam entre fechadas e isoclinais a relativamente abertas, mostrando localmente zonas de charneira isoladas, como dobras desenraizadas, porém com uma assimetria sempre consistente para norte.

Os eixos das dobras associadas à fase Dn dispõem-se no estereograma segundo um círculo máximo, definindo uma guirlanda (Fig. 7) com um máximo principal em $\mathrm{N} 225^{\circ}$, e dois máximos secundários a $\mathrm{N} 115^{\circ}$ e $\mathrm{N} 260^{\circ}$, sendo este último subperpendicular ao máximo da lineação de estiramento mineral. Nota-se nesta figura que a distribuição dos eixos é muito próxima ao plano $\mathrm{C}$ definido no estereograma discutido anteriormente (Fig. 6).

Como as dobras assimétricas mapeadas têm vergência sistemática para NNW-NNE, uma interpretação cinemática da distribuição em guirlanda para os eixos das dobras Dn pode ser feita utilizando-se o modelo proposto por Hansen (1971) (Fig. 8).

Esta figura, que leva em conta a assimetria das dobras segundo o caimento do eixo, o plano de cisalhamento e a atitude da lineação de estiramento mineral sugerem uma movimentação de topo para NNW, compatível com a cinemática obtida por outros indicadores.

Dobras Tardias As dobras tardias na área estudada foram divididas em dois grupos: um grupo mais antigo, com orientação aproximadamente E-W, e outro mais novo, com orientação N-S. Este conjunto de estruturas apresenta relação de superposição com as estruturas anteriores. As dobras do primeiro grupo são contínuas apenas no domínio estrutural I, enquanto que as do segundo, são descontínuas nos dois domínios. Os dois grupos podem ser visualizados no estereograma da foliação principal para toda a área mapeada (Fig. 9).

Outro aspecto a ser salientado é o não reconhecimento de padrões de interferência entre as dobras tardias sobre as dobras da fase principal de deformação (Dn), assim como entre as duas gerações de dobras tardias. Enquanto as dobras Dn são restritas às escalas meso e micro, as dobras tardias são mais frequentes nas escalas meso e macro, com o grupo de dobras E-W tendo sido responsável pela nucleação da estrutura sinformal da Serra do Ijaci (ver Fig. 2).

As dobras tardias mais antigas apresentam traço axial E-W, com eixos de caimento suave para W-SW (Fig. 10).

As dobras deste grupo têm superficies axiais com mergulhos moderados para sul. Estas dobras, em perfil, são assimétricas com vergência para norte, apresentando graus variáveis de fechamento, em geral entre abertas e fechadas. Localmente, apresentam clivagem de crenulação desenvolvida nas zonas de charneira, e estão associadas com superfícies discretas de empurrão, em consequência do intenso cisalhamento ocorrido no flanco curto da estrutura. Na classificação de Ramsay (1967), correspondem a dobras da subclasse 1B. Na classificação de Fleuty (1964), correspondem a dobras sub-horizontais, com superficies axiais de mergulho moderado.

O grupo mais novo é composto por dobras suaves ou abertas, com eixos caindo suavemente para sul, e superfícies axiais com direção N-S e mergulhos subverticais. Estas dobras são evidenciadas principalmente pelas variações de mergulho da foliação principal. A presença descontínua de clivagens espaçadas e crenulações nas zonas de charneira sugere que estas estruturas tenham sido desenvolvidas num nível estrutural mais raso do que as estruturas do grupo mais antigo. Estas dobras, na classificação de Fleuty (1964), correspondem a dobras normais, e na classificação de Ramsay (1967), a dobras da subclasse lB.

Bandas de Cisalhamento Extensionais Estas estruturas são frequentes em todo o domínio da cobertura metassedimentar. São caracterizadas por superficies discretas, anastomosadas, de espaçamento centimétrico a decimétrico, com direções WSW-ENE e E-W, exibindo mergulhos moderados para norte e para sul, respectivamente (Fig. 11).

A assimetria das estruturas sigmoidais indica movimento distensivo para ambos os quadrantes. $\mathrm{O}$ primeiro grupo de estruturas tem desenvolvimento mais localizado do que o segundo grupo, tendo sido registrado apenas no domínio estrutural II.

Zonas de Cisalhamento Dúcteis-Rúpteis Dois grupos distintos de zonas de cisalhamento de alto ângulo foram identificados na área estudada: um com direção E-W, e outro com direção NNE. O primeiro grupo baliza a área de afloramentos dos metassedimentos a sul, enquanto o segundo corresponde ao limite leste dos mesmos (Fig. 2). Aspectos de campo e geomorfológicos sugerem uma importante componente de movimentação normal para estas zonas, muito embora a cinemática destas estruturas não tenha sido observada claramente, em função da natureza dos afloramentos. Outro aspecto importante a ser assinalado com respeito à estas zonas de cisalhamento é o seu 


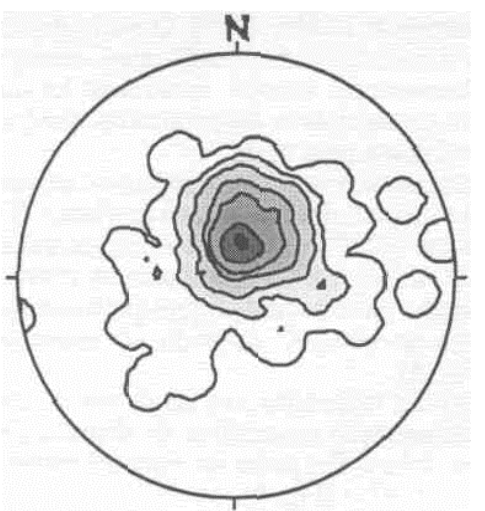

$N=296$

Contornos: $3-1,4-3,1-7,2-11,0-20,1-28,05$

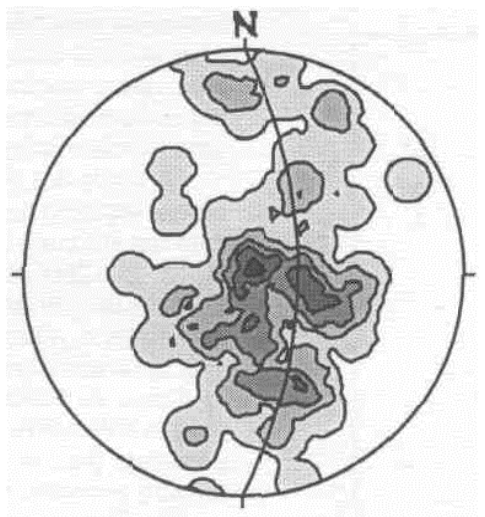
$N=115$
Contomos: $9-2,6-4,3-6,0-7.8 \%$
Guirlanda: 090770

Figura 4 - Estereograma de frequência Figura 5- Estereogratna de frequência (hemis(hemisfério inferior) dos pólos da foliação fério inferior) para as lineações de estiraprincipal (Sn) da área estudada no domínio II mento mineral da área estudada (máximo: (pólo da guirlanda: 270/20). principal (Sn) da área estudada no domínio I (máximo: 180/10). igas do embasamento, representando assim reativação de uma trama estrutural já existente.

DISCUSSÕES E CONCLUSÃO As rochas da área podem ser divididas em dois domínios litoestruturais distintos: Domínio do Embasamento e Domínio da Cobertura.

As rochas do domínio do embasamento são caracterizadas por ortognaisses de composição granítica a granodiorítica, deformados de forma heterogênea, apresentando estrutura foliada a isótropa, localmente bandada, por vezes migmatizados, exibindo leitos descontínuos lateralmente. Nos locais onde a deformação foi mais intensa, com desenvolvimento de texturas miloníticas, observa-se ao microscópio uma recristalização dinâmica do quartzo e do feldspato, evidenciando assim um comportamento dúctil destes minerais. A presença destas feições, juntamente com a segregação de leitos quartzo-feldspáticos nas porções mais deformadas, sugere que a deformação principal tenha ocorrido em condições pelo menos de fácies anfibolito.

Por outro lado, conforme descrito anteriormente, as rochas do domínio da cobertura foram sujeitas à condições de metamorfismo mais baixo, em fácies xisto verde. Os dados sobre microtectônica indicam que este metamorfismo foi concomitante ao desenvolvimento da trama estrutural principal dos metassedimentos.

Os dados aqui apresentados demonstram uma importante diferença metamórfica entre os dois domínios litoestruturais, indicando também que o domínio do embasamento foi submetido a um evento tectônico mais antigo que não afetou o domínio da cobertura. Os dados geocronológicos disponíveis para este embasamento apontam idade transamazônica ou mais antiga (Teixeira 1985, Heilbron et al. 1989). Para os metassedimentos da área estudada não são ainda disponíveis dados isotópicos. Embora esta unidade venha sendo correlacionada ao Grupo São João del Rei (Formações Barroso e Prados, esta última equivalente a Formação Macaia) (Ebert 1984), o posicionamento desta última ainda se encontra em aberto. Andreis et al. (1989a) e Ribeiro et al. (1990), por exemplo, posicionam este grupo entre os ciclos Transamazônico e Uruaçuano. Os autores consideram a fase de deformação tangencial (D1 e D2) como sendo de idade uruaçuana, enquanto a fase de deformação transcorrente (D3), brasiliana (Heilbron et al. 1989 , Ribeiro et al. 1990). Alternativamente, estas deformações (D1, D2 e D3) têm sido consideradas como de idade brasiliana, em um modelo de deformação transpressiva, colocando assim um modelo tectônico de evolução monocíclico (Machado \& Endo 1993a, 1993b, Endo \& Machado 1993). Apesar das diferenças de opiniões sobre a idade da deformação/metamorfismo deste grupo, é evidente que estes eventos são claramente posteriores a sedimentação dos ciclos Carandaí e Andrelândia, pois as deformações afetam igualmente os quatro ciclos deposicionais. A idade da sedimentação dos ciclos Carandaí e Andrelândia, pelos próprios dados geocronológicos $(\mathrm{Sm} / \mathrm{Nd})$ apresentados por Ribeiro et al. (1990), sobre diques que afetam os ciclos anteriores (Tiradentes e Lenheiro), poderia ser mais jovem do que 1300 Ma. Neste caso, a sedimentação poderia ter se iniciado no Mesoproterozóico (Uruaçuano) ou até mesmo no Neoproterozóico (Brasiliano). Estes dados sugerem que a deformação que afetou estas unidades remonta provavelmente o Brasiliano, fato este que é corroborado pelas idades obtidas para o domínio Andrelândia (Machado et al. 1996).

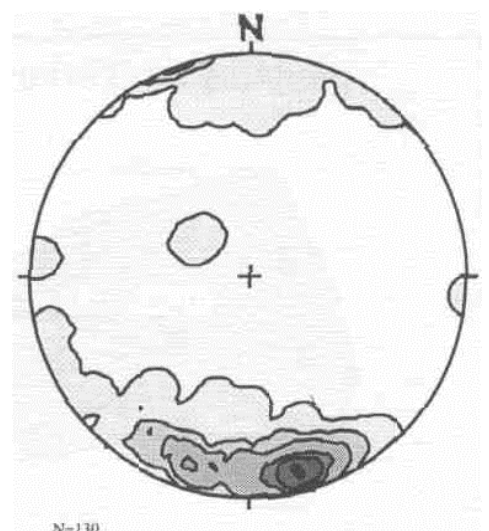

$N=130$
Contomos: $, 2-3,1-6,2-10,0-13,9-17,7-23,9 \%$
A discussão acima, juntamente com os dados obtidos no presente trabalho, permite considerar a fase de deformação principal (Dn), que afetou as rochas metassedimentares na área estudada, como sendo posterior a deformação principal registrada nas rochas do domínio do embasamento, provavelmente de idade brasiliana, evidenciando assim um discordância estrutural e metamórfica entre a cobertura e o embasamento. Esta discontinuidade mecânica, determinada pelo contraste reológico entre estes dois domínios litoestruturais, nas condições metamórficas vigentes durante a deformação principal (tangencial) da cobertura, foi responsável pela concentração da deformação dúctil nesta última. Esta fase de deformação da cobertura é o resultado de um cisalhamento não-coaxial de baixo ângulo, de natureza compressiva, com movimentação de topo para NNW.

$\mathrm{O}$ contraste reológico entre as rochas da cobertura e do embasamento, juntamente com o caráter não-coaxial da deformação Dn e de texturas miloníticas nas rochas da cobertura, sugere uma aloctonia destas últimas em relação às primeiras. A relação geométrica entre o plano de cisalhamento e a lineação de estiramento mineral sugere que a deformação principal tenha ocorrido num modelo de rampa frontal.

O padrão em guirlanda, desenhado pelos eixos das dobras Dn em projeção estereográfica, é interpretado como resultante do processo de cisalhamento não-coaxial imposto às rochas da cobertura (Hudleston 1986, Mies 1991). Vários modelos têm sido propostos para explicar este padrão, gerado pela reorientação dos eixos que inicialmente seriam formados perpendiculares ou oblíquos à direção de transporte (Bryant \& Reed 1969, Sanderson 1973, Escher \& Watterson 1973, Williams 1978, Alsop 1992 dentre outros) ou, então, gerado pela própria formação das dobras com eixos em várias direções em relação à de transporte (Hansen 1971, Fossen \& Rikkelid 1992).

Independentemente dos modelos propostos para explicar o giro dos eixos das dobras para a direção de transporte, é consenso por parte dos autores de que os eixos se tornam efetivamente paralelos somente em regiões de alta deformação. Neste sentido, a área estudada apresenta uma deformação interna relativamente menor, quando comparada à áreas onde os eixos das dobras são efetivamente paralelos à direção de transporte, embora, localmente, a deformação tenha sido intensa, conforme indicado pela presença de dobras em bainha (Skjernaa 1989, Henderson 1993, Mies 1993) e, também, pelo desenvolvimento de zonas onde a foliação principal apresenta uma trama dominantemente planar, contíguas à zonas onde predominam dobras (Gosh \& Sengupta 1987).

As fibras de carbonato no plano de foliação principal, indicando a mesma vergência da tectônica dúctil da fase Dn, sugerem que o mesmo vetor cinemático tenha permanecido ativo mesmo em níveis estruturais mais rasos.

Como descrito anteriormente, dois grupos de dobras tardias se superpõem à estruturação principal: um grupo de dobras com eixos caindo suavemente para $\mathrm{W}$ a SW e outro com eixos caindo para S. Este último é interpretado como posterior, pois suas características geométricas e estruturas associadas sugerem que tenham se desenvolvido em níveis estruturais mais rasos. $\mathrm{O}$ primeiro grupo pode ser interpretado de duas formas distintas: como estruturas tardi-Dn ou como reflexo da atuação concomitante da estrutura do embasamento. No primeiro caso, como os eixos destas dobras estão orientados em 


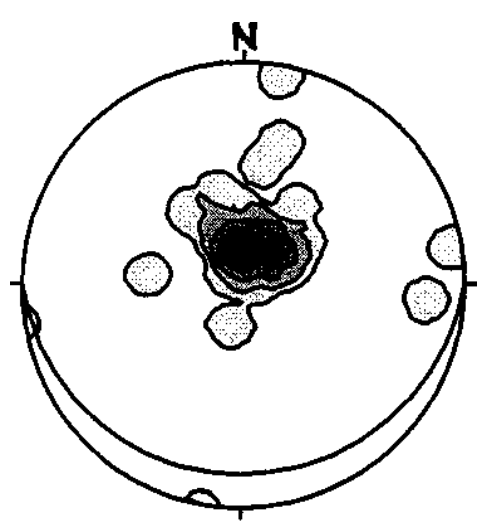

$\mathrm{N}-52$

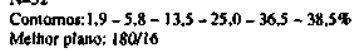

ura 6 - Ester

Estereograma de frequência Figura 7 - Estereograma de frequência Figura 8 - Estereograma de frequência (hemisfério inferior) dos pólos dasfoliações $C$ (hemisfério inferior) para os eixos das dobras (hemisfério inferior), mostrando a rotação dos da área estudada (máximo: 180/16).

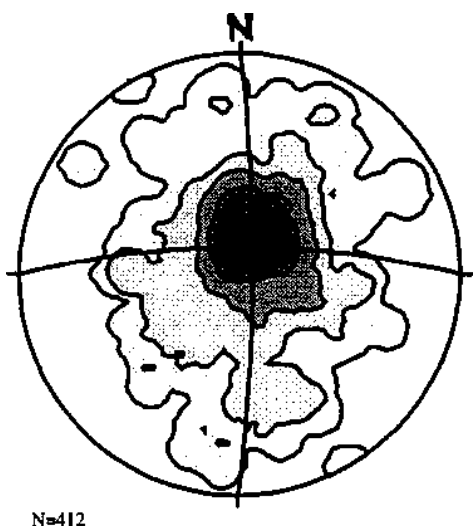

Comomos, $2-1,0-2,7-6,1-10,2-15,0-16,8 \%$ Guirlandas: 000080; 09085

Figura 9 - Estereograma de frequência (hemisfério inferior) para afoliação tectônica principal de toda a área estudada.

alto ângulo com a Hneação de estiramento mineral, e apresentam uma assimetria compatível com os demais indicadores cinemáticos observados, tais estruturas poderiam representar dobras tardi-Dn, refletindo, assim, os estágios finais da deformação principal (Dehler 1996). Evidências microestruturais e de campo reforçam esta hipótese. Neste contexto, as fibras de carbonato poderiam ser reflexo do deslizamento interestratal associado a este próprio dobramento, ocorrido nos estágios finais da fase Dn. No segundo caso, deve ser considerada a importância das estruturas do embasamento na deformação da cobertura, a qual na região possui direção próxima de E-W, com mergulhos subverticais. Neste sentido, a reativação concomitante desta trama estrutural no embasamento, durante a fase Dn nos metassedimentos, poderia nuclear estas dobras. Em ambas as hipóteses, a geração das dobras ocorreria durante a própria fase Dn. E importante salientar que os domínios estruturais delimitados neste trabalho, resultantes da própria estruturação final dos metassedimentos, são interpretados como decorrentes sobretudo das dobras com eixos W-SW.

As zonas de cisalhamento tardias representariam estruturas de reativação do embasamento, sendo, portanto, difícil de posicioná-las precisamente no tempo. É possível mesmo que estas estruturas estivessem ativas durante a fase de deformação principal que afetou as rochas metassedimentares, funcionando neste caso como estruturas que acomodaram a deformação, influenciando sobretudo na partição do quadro deformacional. A movimentação tardia destas zonas de cisalhamento foi acompanhada de uma importante componente normal ou inversa, cujo papel foi decisivo na preservação dos metassedimentos.

Outro aspecto a ser discutido é a questão do agrupamento das estruturas da cobertura em fases de deformação. Dois modelos principais podem ser adotados: um modelo de deformação sequencial, com

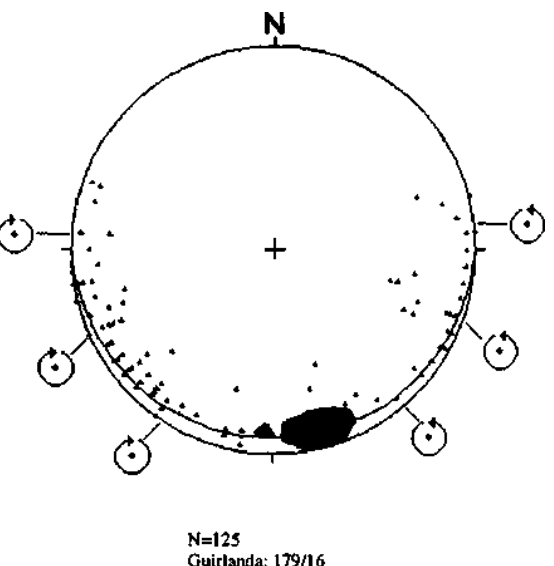
dobras em relação a Hneação de estiramento-mineral durante um cisalhamento simples.

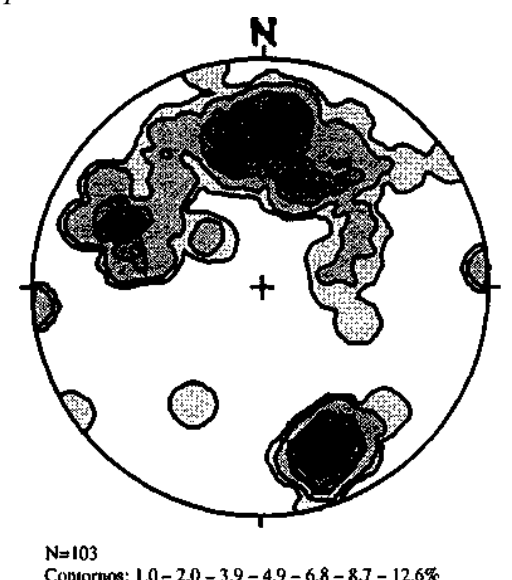

Figura 11 - Estereograma de frequência (hemisfério inferior) para as superficies extensionais da área estudada (pólo da guirlanda: fases de dobramentos superpostos, ou um modelo de deformação progressiva, onde a geração das diferentes geometrias de estruturas são explicadas durante o mesmo evento deformacional. Neste modelo, nos domínios externos de uma faixa dobrada, as anisotropias do embasamento passam a ter um papel importante na nucleação e evolução das estruturas. $\mathrm{O}$ conjunto de elementos geométricos e cinemáticos aqui discutidos são mais compatíveis com o modelo de deformação progressiva.

As rochas metassedimentares da área estudada são caracterizadas por uma estruturação subhorizontal, com mergulhos suaves para sul. A cinemática associada à esta estruturação sugere uma movimentação de topo para NNW, em direção ao núcleo mais estável, representado pelo Cráton do São Francisco. Esta observação é compatível com uma situação geotectônica de foreland. Neste sentido, a área estudada estaria localizada na porção mais externa de um orógeno, enquanto a sua parte interna se situaria mais a sul. Os metassedimentos da região de Ijaci podem ser interpretados como uma lasca de empurrão, sem conexão com unidades correlatas, agora constituindo uma klippe.

Estruturalmente, a articulação da área mapeada com os metassedimentos localizados mais a sul, nas proximidades da cidade de Lavras, é problemática. Nesta região, Ribeiro et al. (1990) assinalam transporte tectônico de topo para leste. Este fato sugere uma articulação entre áreas com transporte tectônico praticamente ortogonais. Isto poderia ser interpretado de duas formas: ou as estruturas com transporte tectônico para norte são desvinculadas das estruturas com transporte para leste e, neste caso, seriam mais antigas, ou, alternativamente, estas estruturas seriam o resultado de um escape tectônico das unidades metassedimentares, decorrente da movimentação da Cunha de Guaxupé para leste. 
Agradecimentos À Fundação de Amparo a Pesquisa do Estado de São Paulo (FAPESP - Proc. 93/4827-1), pelo suporte financeiro para realização deste trabalho. Ao Prof. Dr. Issamu Endo (UFOP), pela participação nas primeiras etapas de campo e discussões. Aos geólogos
Heloísa Rodrigues de Souza Dehler, Mateus Delatim Simonato, Arlindo Akio Yamato e Vilmario Antunes, pelas discussões e sugestões nas várias etapas do trabalho e a dois revisores anônimos da Revista Brasileira de Geociências, pela análise critica e sugestões ao texto original.

\section{Referências}

Alsop, G. I. 1992. Progressive deformation and the rotation of contcmporary fold axes in the Ballybofey Nappe, north-west Ireland. Geological Journal, 27: 271-283.

Andreis, R.R.; Ribeiro, A.; Paciullo, F.V.P. 1989a. Ciclos deposicionais no proterozóicoda folhas Barcacena e Divinópolis (setor sul), 1: 250.000, Minas Gerais: bases para interpretação da evolução das bacias sedimentares. In: SBG, Simpósio de Geologia do Sudeste, 1, Rio de Janeiro, Boletim de Resumos Expandidos: 97-98.

Andreis, R.R.; Ribeiro, A.; Paciullo, F.V.P 1989b. Caracterização preliminar dos ciclos deposicionais proterozóicos no sudeste de Minas Gerais. In: SBG, Simpósio de Geologia do Sudeste, 1, Rio de Janeiro, Boletim de Resumos Expandidos: 101-102.

Barbosa, O. 1954. Evolution du Geossinclinal Espinhaço. In: International Geological Congress, Argélia, Comptes Rendus, section xiii, 19 e session: 1-37.

Berth, D.; Choukroune, P.; Jegouzo, P. 1979. Orthogneiss, mylonite and noncoaxial deformalion of granites: the example of the South Armorican shear zone. Journal of Structural Geology, 1(1): 3|-42.

Bryant, B. \& Reed, J.C. 1969. Significancc of lineation and minor folds ncar thrust fault in the southern Appalachians and the British and Norwegian Caledonides. Geological Magazine, 106(5): 412-429.

Campos Neto, M. C. 1991. A porção ocidental da Faixa Alto Rio Grande - Ensaio de Evolução Tectônica. Instituto de Geociências, Universidade de São Paulo, São Paulo, Tese de Doutoramento, 210p.

Campos Neto, M.C.; Perrota, M.M.; Pcloggia, A.U.G.; Figueiredo, M.C.H. 1990. A porção ocidental da Faixa Alto Rio Grande (SP-MG). In: SBG, Congresso Brasileiro de Geologia, 36, Natal, Anais...6: 2615-2630.

Dehler, N. M. 1996. Análise Geométrica e Cinemática dos metassedimentos da região de Ijaci, sul do estado de.Minas Gerais. Instituto de Geociências, Universidade de São Paulo, São Paulo, Dissertação de Mestrado, 126p.

Dehler, N. M.; Machado, R.; Dehler, H. R. S.; Simonato, M. D. 1996. Análise geométrica cinemática das rochas metassedimentarcs da região de Ijaci, sul de Minas Gerais c implicações tectônicas regionais. In: SBG-BA, Congresso Brasileiro de Geologia, 39, Salvador, Anais... 1: 450-451.

Dehler, N. M.; Machado, R.; Endo, L; Simonato, M. D. 1995. Contribuição ao estudo estrutural cinemático de metassedimentos correlacionáveis ao Grupo São João del Rei na região de Ijaci, norte de Lavras, MG. In: SBG-MG, Simpósio de Geologia de Minas Gerais, 8 , Diamantina, Anais... $13: 123-124$.

Ebert, H. 1955. Pesquisa na parte sudeste de Minas Gerais c Polígono das Secas. In: Relatório Anual do Diretor-DGM/DNPM, ano de 1954, publicado cm 1955, Rio de Janeiro, p.79-89.

Ebert, H. 1956a. Resumo dos resultados obtidos no ano de 1955 no sul do estado de Minas Gerais. In: Relatório Anual do Dirctor-DGM/DNPM, ano de 1955, publicado cm 1956, Rio de Janeiro, p. 62-81.

Ebert, H. 1956b. A tectônica do sul do Estado de Minas Gerais c regiões adjascentcs. In: Relatório Anual do Diretor-DGM/DNPM, Rio de Janeiro, p.97-107.

Ebert, H. 1957. Beitrag zur Gliederung das Präkambriuns in Minas Gerais. Geologische Rundschau, 45:471-521.

Ebert, H 1958. Discordâncias pré-cambrianas em Carandaí, Minas Gerais. Boletim 183, DNPM-DGM, Rio de Janeiro, $48 \mathrm{p}$.

Ebert, H. 1968. Ocorrências de fácies granulíticas no sul de Minas Gerais e cm áreas adjacentes em dependência da estrutura orogênica: hipóteses sobre sua origem. Anais da Academia Brasileira de Ciências, 40 (Supl.): 215-229.

Ebert, H. 1971. Os Paraibídes entre São João del Rei, Minas Gerais c Itapira, São Paulo, c a bifurcação entre Paraibídes e Araxaídcs. In: SBG, Congresso Brasileiro de Geologia, 25, São Paulo, Resumo das Comunicações, 1: 177-178.

Ebert, H. 1984. Os Paraibídes entre São João del Rei c Itapira c a bifurcação entre Paraibídes c Araxaídes (in memorian). Publicação Especial, SBG-SP, 12/84: 72-103.

Ebert, H. D.; Neves, M. A.; Hasui, Y, Szatmari, P.; Aires, J.R. 1993a. Evolução dos cinturões de cisalhamento entre os blocos São Paulo, Vitória c Brasília através da tectônica colisional oblíqua - uma modelagem fisica. In: SBG, Simpósio Nacional de Estudos Tectônicos, 4 , Belo Horizonte, Anais... 12: 254-258.

Ebert, H. D.; Hasui, Y.; Sartorato, G.; Almeida, S. H.; Costa, J. B. S. 1993b. Arcabouço Estrutural e Tectônica Transpressiva das Faixas Móveis da borda Sul c Sudeste do Cráton do São Francisco e da Sintaxe de Guaxupé. In: SBG, Simpósio Nacional de Estudos Tectônicos, 4rancisco e da Sintaxe de Guaxupe. In.

Endo, I. 1997. Regimes Tectônicos do Arqueano e Proterozóico no interior da Placa São Franciscana: Quadrilátero Ferrífero e Áreas adjascentes, Minas Gerais. Instituto de Geociências, Universidade de São Paulo, São Paulo, Tese de Doutoramento, 382p

Endo, I. \& Machado, R. 1993. Sistema de Cisalhamento Transatlântico: Um Modelo Tcctônico Transpressional para o Neoproterozóico do Brasil Oriental. In: SBG, Simpósio Nacional de Estudos Tectônicos, 4, Belo Horizonte, Anais. 12: 356-359.

Escher, A. \& Watterson, J. 1974. Stretching fabrics, folds and crustal shortcning. Tectonophysics,

Fleuty, M. J. 1964. The descriptions of folds. Proceedings of Geological Association ofLondon, 75:461-492.

Fossen, H. \& Rikkelid, E. 1990. Shear structures in lhe Oygarden arca, West Norway. Tectonophysics, 174: 385-397.

Gosh, S. K. \& Sengupta, S. 1987. Progressive development of structures in a ductilc shear zonc Journal of Structural Geology, 9(3):277-287.

Hanmer, S. \& Passchier, C. W. 1990. Shear Sensc Indicators: a rcview. Geological Survey of Canada Paper, 90-17: 72p.

Hansen, E. 1971. Strain Fácies. Berlim.Springer-Verlag, 207p.

Hasui, Y. \& Oliveira, M.A.F. 1984. a Província Mantiqueira: Setor Central. In: ALMEIDA F.F.M. \& HASUI, Y.(Coord). O Pré-Cambriano do Brasil. São Paulo, Ed. Edgard Blücher, 378p

Heilbron, M. 1993. Evolução tectono-metamórfica da seção Bom Jardim de Minas, MG e Barra do Pirai, RJ, Setor Central da Faixa Ribeira. Instituto de Geociências, Universidade de São Paulo, São Paulo, Tese de Doutoramento, 268p.

Heilbron, M.; Gonçalves, M. L.; Teixeira, W.; Trouw, R.A.J.; Padilha, A. V. ; Kawashita, K. 1989. Geocronologia entre Lavras, São João del Rei, Lima Duarte c Caxambu (MG). Anais da Academia Brasileira de Ciências, 61: 177-199.
Heilbron, M.; Graduado, A. D. R.; Silva, L. G. E.; Nogueira, J. R.; Trouw, R. A. J.; Polonia, J. A. L. 1994. A compartimentação tectônica da seção Conceição do Ibitipoca -Valença, segmento central da Faixa Ribeira. In: SBG, Congresso Brasileiro de Geologia, 38, Camboriú, Boletim de Resumos Expandidos, 2: 55-56.

Henderson, J. R. 1993. Analysis of folds and cleavagc in carbonates, Appalachians Piedmont, southcastem Pennsylvania. Ahstract and Programm of Geological Society of America, 2 (25): 23.

Hudleston, P. J. 1986. Extracting Information from folds in Rocks. Journal of Geological Education, 34: 237-245.

Listcr, G. S. \& Snoke, A. W. 1984. S-C milonites. Journal of Structural Geology, 6 (6): 617-638

Machado, R. \& Endo, I. 1993a. A Megaestrutura em flor positiva do Vale do Paraíba do Sul no Rio de Janeiro e suas Implicações Tectônicas Regionais. In: SBG-RJ, Simpósio de Geologia do Sudeste, 3, Rio de Janeiro Atas: 208-213

Machado, R. \& Endo, I. 1993b. Cinturão de Cisalhamento Attântico: Um Exemplo de Tectônica Transpressiva Neoprotcrozóica. In: SBG, Simpósio Nacional de Estudos Tectônicos, 4 , Belo Horizonte Anais... 12: 189-191.

Machado, R. \& Endo, I. 1994. Superposição Cinemática Brasiliana no Cinturão de Cisalhamento Atlântico c na Cunha de Guaxupé. In: SBG, Congresso Brasileiro de Geologia, 38, Camboriú, Boletim de Resumos Expandidos, 1: 269-271.

Machado, R. \& Dehler, N. M. 1995. Dobras em bainha em rochas metassedimentarcs do Grupo São João del Rei na região de Ijaci, norte de Lavras (MG): Caracterização Geométrica c Cinemática. In: SBG, Simpósio de Geologia do Sudeste, 4, Águas de São Pedro, Boletim de Resumos: 116.

Machado, N; Valladarcs, C. S.; Heilbron, M.; Valeriano, C. M. 1996. U/Pb gcochronology of the central Ribeira Belt: implicalions for the cvolution of brasiliano orogeny. Precambrian Research, 79:347-361.

Mies, J. W. 1991. Planar dispcrsion of folds in ductile shear zoncs and kinematic interpretation of fold hingc girdlcs. Journal of Structural Geology, 13 (3): 281-297.

Mies, J. W. 1993. Structural analysis of sheath folds in the Sylacauga Marble Group, Talladega slate belt, southern Appalachians. Journal of Structural Geology, 15 (8): 983-993.

Passchier, C. W. \& Trouw, R. A. J. 1994. Microtectonics. Berlim, Springucr-Verlag, 289p.

Ramsay, J.G. 1967. Folding and Fracturing of rocks. New York, McGraw-Hill, 568p.

Ribeiro, A.; Paciullo, F. V. P.; Andreis, R.; Trouw R. A. J.; Heilbron, M. 1990. Evolução policíclica prolerozóica no sul do Cráton do São Francisco:análisc da região de São João Del Rcy c Andrelândia (MG). In: SBG, Congresso Brasileiro de Geologia, 36, Natal, Anais... 6:2605-2614.

Sanderson, D. J. 1973. The development of folds axes oblique to the Regional Trend. Tectonophysics, 16:.55-70.

Skjcrnaa, L. 1989. Tubular folds and sheath folds: definitions and conceptual models for their devclopment, with cxamples from the Graspesvare área, northcrn Sweden. Journal of Structural Geology, 11 (6): 689- 703.

Tassinari, C.G. 1988. As Idades das Rochas e dos Eventos Metamórficos da porção SE do estado de SP e sua evolução crustal. Instituto de Geociências, Universidade de São Paulo, São Paulo, Tese de Doutoramento, 336p.

Teixeira, W. 1985. A evolução geotectônica da porção meridional do cráton do São Francisco, com base em interpretações geocronológicas. Instituto de Geociências, Universidade de São Paulo, São Paulo, Tese de Doutoramento, 207p.

Trouw, R.A.J. \& Pankhurst, RJ. 1993. Idades Radiométricas ao sul do Cráton do São Francisco: região da folha Barbaccna, Minas Gerais. In: SBG, Simpósio do Cráton do São Francisco, 2, Salvador, Anais...: 260-261.

Trouw, R. A. J. 1995. Uma avaliação de modelos cinemáticos propostos para o megassinformal do Vale do Paraíba do Sul, baseada em lineaçõcs de estiramento. In: SBG-RS, Simpósio Nacional de Estudos Tcctônicos, 5, Gramado, Boletim de Resumos Expandidos: 103-104.

Trouw, R.A.J; Ribeiro,A.; Paciullo, F.V.P. 1980. Evolução Estrutural c Metamórfica de uma área a SE de Lavras, Minas Gerais. In: SBG, Congresso Brasileiro de Geologia, 30, Camboriú, Anais... 5: 2273-2284.

Trouw, R.A.J; Ribeiro.A.; Paciullo, F.V.P. 1983. Geologia Estrutural dos Grupos São João del Rey, Carrancas c Andrelândia, sul de Minas Gerais. Anais da Academia Brasileira de Ciências, 55( 1 ) : 71-85.

Trouw, R.A.J; Ribciro.A.; Paciullo, F.V.P. 1986. Contribuição à Geologia da Folha Barbaccna-1:250000. In: SBG, Congresso Brasileiro de Geologia, 34, Goiânia, Anais... 2: $974-986$.

Trouw, R.A.J; Ribeiro.A.; Paciullo, F.V.P. 1994. A Faixa Alto Rio Grande rcinterprctada como zona de interferência entre a Faixa Brasília e a Faixa Ribeira. In: SBG, Congresso Brasileiro de Geologia, 38, Camboriú, Boletim de Resumos Expandidos, 1: 234-235.

Trouw, R.A.J; Ribciro.A.; Paciullo, F.V.P.; Dayan, H. 1982. Análise da deformação de uma área a SE de Lavras, Minas Gerais. In: SBG, Congresso Brasileiro de Geologia, 31, Salvador, Anais...1: 187-198.

Trouw, R. A. J; Ribeiro, A.; Paciullo, F. V. P.; Heilbron, M. 1984. Os Grupos São João del Rey, Carrancas c Andrclândia interpretados como a continuação dos Grupos Araxá e Canastra. In: SBG, Congresso Brasileiro de Geologia, 33, Rio de Janeiro, Anais... $7: 3227-3239$.

Turncr, F. J. \& Wciss, L. E. 1963. Structural Analysis of Metamorphic Tectonites. New York, McGraw-Hill, 545p.

Wernick, E.; Fiori, A. P.; Beltcncourt, J. S.; Choudhuri, A. 1981. A Tectônica Rígida do fim do ciclo Brasiliano e sua implicação na estruturação da borda sul c sudoeste do Cráton do São Francisco: tentativa de um modelo preliminar. In: SBG-BA, Simpósio do Cráton do São Francisco c suas Faixas Marginais, 1, Salvador, Anais...: 164-168.

Williams, G. D. 1978. Rotation of contcmporary folds into the X direction during ovenhrust processes in Lakscfjord, Finmmark. Tectonophysics, 48:29-40.

Yardley, B. 1992. An Introduction to Metamorphic Petrology. London, Longman Earth Sciences Series, 248p.

Manuscrito A-926

Recebido em 15 de julho de 1997 Revisão dos autores em 22 de setembro de 1998 Revisão aceita em 30 de setembro de 1998 